\title{
ANALISA KUALITAS LAYANAN TERHADAP KEPUASAN NASABAH DI PT. BANK MANDIRI (PERSERO) TBK. CABANG SIDOARJO GEDANGAN
}

Pierre Patarianto (lppm_mahardhika@yahoo.co.id)

Sekolah Tinggi Ilmu Ekonomi Mahardhika

\begin{abstract}
This study aimed to analyze the quality of service on customer satisfaction in PT. Bank Mandiri (Persero) Tbk. Sidoarjo branch Gedangan, the variables used in this study was the quality of service consisting of Reability, responsiveness, assurance, empathy, and tangible as well as the level of customer satisfaction. This study was conducted to spread out questionnaires to 72 customers in the bank branch Gedangan Sidoarjo. To see the effect of service quality on customer satisfaction conducted sampling of respondents involved in the sampling process. Test equipment used is the technique of multiple linear regression analysis with SPSS 17.0 software. From the results of multiple regression analysis in F test obtained Fhitung 22 285> of F Table of 2346 or by the significant value of 0000 in which the significance value is less than the significance level $=0.05$. it can be concluded that Ho refused and Ha accepted, it means reliability $\left(X_{1}\right)$, responsiveness $\left(X_{2}\right)$ assurance $\left(X_{3}\right)$, empathy $\left(X_{4}\right)$, and tangible $\left(X_{5}\right)$ together have a significant impact on customer satisfaction $(Y), T$ test to determine the effect obtained partial realibility of 2611; variable responsiveness of 2155; variable assurance amounted to 2,383; emphaty variables for 4328; tangible variables for 2219. whose value is greater than ttable which amounted to 1,997, which means stating that the variable stress reliability $\left(X_{1}\right)$, responsiveness $\left(X_{2}\right)$, assurance $\left(X_{3}\right)$, empathy $\left(X_{4}\right)$, and tangible $\left(X_{5}\right)$, individually (partial) influence to variable customer satisfaction.
\end{abstract}

Key words: Realibility, Rensponsiveness, Assurance, Emphaty, Tangible, Customer Satisfaction

\section{PENDAHULUAN}

Dalam era perdagangan bebas, setiap perusahaan menghadapi persaingan dan jumlah pesaing menuntut perusahaan untuk selalu memperhatikan kebutuhan dan keinginan konsumen dengan cara memberikan pelayanan yang lebih memuaskan dari pada yang dilakukan perusahaan pesaing. Dengan demikian, hanya perusahaan yang berkualitas yang dapat bersaing dan menguasai pasar. Kualitas memiliki hubungan erat dengan kepuasan pelanggan. Kualitas memberikan suatu dorongan kepada pelanggan untuk menjalin ikatan hubungan yang kuat dengan perusahaan. Dalam jangka panjang, ikatan seperti ini memungkinkan perusahaan untuk memahami dengan seksama harapan pelanggan serta kebutuhan mereka. Dengan demikian, perusahaan dapat meningkatkan kepuasaan pelanggan dimana perusahaan memaksimumkan pengalaman pelanggan yang menyenangkan dan meminimumkan pengalaman pelanggan yang kurang menyenangkan (Atmawati dan Wahyuddun, 2007). Kepuasan pelanggan saat ini menjadi faktor yang paling penting bagi tiap - tiap perusahaan, terutama perusahaan yang bergerak dibidang industri jasa. Fokus pada hal ini dilakukan agar perusahaan tersebut memiliki nilai kompetitif untuk dapat bersaing dengan perusahaan lainnya. Bagi perusahaan yang bergerak diindustri jasa seperti perbankan, tingkat kepuasan pelanggan dipengaruhi terutama oleh kualitas pelayanan frontliner bank yaitu security, teller dan customer service. Mereka sebagai ujung tombak informasi dari perusahaan 
perbankan harus dapat bergerak dengan cepat, ramah, dan cekatan dalam melayani nasabah sebagai pelanggan diperusahaan.

Dalam perbankan, masalah pelayanan merupakan hal yang sangat penting karena pelayananlah (service) yang dianggap mampu mempengaruhi minat masyarakat terhadap bank. Pelayanan merupakan strategi yang dapat membedakan antara bank satu dengan bank yang lainnya.Salah satu strategi yang dapat menunjang keberhasilan dalam bisnis perbankan adalah berusaha menawarkan kualitas jasa dengan kualitas pelayanan yang tinggi yang nampak dalam kinerja yang tinggi dalam performa dari pelayanan yang ada. Dalam menghadapi persaingan, ada beberapa dimensi kualitas pelayanan yang dapat mempengaruhi perilaku nasabah, diantaranya persepsi pelanggan terhadap kualitas layanan meliputi sarana Kehandalan (Reability), Daya tanggap (Responsieness), Jaminan (Assurance), Empati (Emphaty), Bentuk Fisik (Tangible).

PT. Bank Mandiri (Persero) Tbk. merupakan salah satu instansi pelayanan jasa dalam dunia perbankan, termasuk PT. Bank Mandiri (Persero) Tbk. Cabang Sidoarjo Gedangan sebagai objek penelitian ini, alasannya karena terjadi kenaikan jumlah debitur. Dan persaingan bisnis perbankan menjadi sangat ketat dan tajam, kecenderungan itu terlihat, antara lain dengan semakin banyaknya bank - bank mengadakan promosi dengan menggelar program undian berhadiah besar - besaran kepada nasabah. Bank - bank akan terus berupaya meraih dana murah dari masyarakat dalam bentuk tabungan dan giro. Dengan demikian, kompetisi perbankan dalam menggaet dana pihak ketiga (DPK) akan semakin bersaing. Sebagaimana fungsinya selaku lembaga keuangan, bank melakukan kegiatan yaitu menghimpun dana masyarakat dan menyalurkan ke dalam bentuk kredit. Penghimpunan dana masyarakat dilakukan dalam bentuk tabungan, giro, deposito, dan lain-lain. Sedangkan penyalurannya dilakukan melalui kredit, baik kepada perorangan maupun perusahaan.

Akibat dari persaingan yang semakin ketat, bank dituntut untuk bekerja lebih efektif dan efisien agar dapat memberikan kualitas pelayanan yang terbaik kepada nasabahnya. Kebanyakan bank di Indonesia terlalu bernafsu dalam mengejar pertumbuhan yang tinggi ketimbang memperhatikan mutu pelayanan mereka. Padahal jika dilihat dalam jangka panjang, mutu pelayanan yang baik sangat diperlukan oleh industri perbankan. Terutama dalam strategi dalam menghadapi persaingan yang kian ketat. Pelayanan merupakan salah satu hal penting yang dijadikan strategi dalam memenangkan persaingan, terutama dalam kompetisi di sektor retail banking. Untuk bank yang hanya mengandalkan suku bunga sebagai alat utama untuk memenangkan persaingan ini tidak dapat diandalkan lagi. Tetapi itu semua tergantung dari bagaimana bank tersebut menerapkan kualitas pelayanannya agar dapat memuaskan dan mempertahankan nasabah. Di pihak lain mungkin saja kualitas pelayanan yang diberikan sudah dirasakan baik oleh bank, tetapi karena tingkat ekspektasi nasabah semakin tinggi, sehingga nasabah merasa bahwa pelayanan yang diberikan tidak sesuai bahkan jauh di bawah harapannya. Hal seperti ini dapat menimbulkan kekecewaan 
nasabah, akhirnya nasabah dapat pindah ke bank lain yang pelayanannya jauh lebih baik. Menyadari betapa pentingnya kualitas pelayanan dalam dunia perbankan karena berkaitan dengan citra bank yang terbentuk dalam masyarakat, Bank Mandiri berusaha untuk mengantisipasi hal ini.

Usaha yang dilakukan adalah dengan memberikan pelayanan sebaik mungkin kepada nasabah dan selalu menekankan pada kualitas jasa produk yang mampu memberikan kemudahan dan kepuasan nasabah. Adapun untuk mendukung upaya peningkatan kualitas pelayanan Bank Mandiri memiliki suatu standar pelayanan salah satunya adalah sikap " TIPCE " yang merupakan budaya service perusahaan yaitu Trust Intergrity Profesionalisme Costumer focus Excelent, diharapkan sikap ini akan memberikan mutu pelayanan yang baik dan ramah kepada setiap nasabah. Untuk dapat memberikan pelayanan yang baik dan memuaskan, bank membutuhkan karyawan yang berkualitas yang harus ada dalam semua tingkat manajemen baik yang berhubungan langsung dengan nasabah maupun tidak.

Alasan yang mendasari topik penelitian ini adalah bahwa setiap perusahaan perbankan dalam mempertahankan nasabahnya, perusahaan tersebut harus mampu memberikan pelayanan yang baik kepada nasabah. Kualitas pelayanan terhadap kepuasan pelayanan terhadap kepuasan nasabah merupakan strategi yang dapat diimplementasikan untuk menunjang tujuan tersebut. Karena perusahaan perbankan merupakan salah satu penyedia jasa yang menerapkan keramah tamahan dalam hubungan dengan nasabah. Dengan demikian pentingnya dilakukan analisa untuk mengetahui persepsi nasabah terhadap layanan produk dan jasa yang telah dirasakan selama ini yang diharapkan dapat memudahkan pihak bank untuk melakukan strategi layanan produk dan dapat meningkatkan kualitas pelayanan service bank kepada nasabah. Sesuai dengan latar belakang yang telah diuraikan di atas, maka peneliti tertarik untuk memahami dan membahas tentang kualitas pelayanan terhadap kepuasan nasabah, dalam bentuk penelitian tentang Analisa Kualitas Layanan Terhadap Kepuasan Nasabah Di PT. Bank Mandiri (PERSERO) TBK. Cabang Sidoarjo Gedangan.

\section{METODE PENELITIAN}

Jenis penelitian ini adalah jenis penelitian kuantitatif, berdasarkan teori, maka penelitian ini dilakukan untuk mendapatkan data yang kemudian diangkakan sesuai dengan metode rasional, dimana data diperoleh dari sampel populasi penelitian.Jenis data yang digunakan dalam penelitian ini berupa kuantitatif dalam bentuk angka yang didapat melalui penyebaran kuesioner pada nasabah PT. Bank Mandiri (Persero) Tbk. cabang Sidoarjo Gedangan. Sumber data yang digunakan dalam penelitian ini adalah data primer, yaitu data diperoleh secara langsung dari sumbernya, yang didapat dari penyebaran kuesioner pada nasabah PT. Bank Mandiri (Persero) Tbk. cabang Sidoarjo Gedangan. Menurut (Sugiono, 2008), populasi adalah wilayah generalisasi yang terdiri atas obyek atau subyek yang mempunyai kualitas dan karakteristik tertentu yang 
ditetapkan oleh peneliti untuk dipelajari dan kemudian ditarik kesimpulannya. Target populasi dari penelitian ini adalah nasabah pengguna jasa PT. Bank Mandiri (Persero) Tbk cabang Sidoarjo Gedangan yaitu 250 Nasabah. Dengan karakteristik nasabah yang jenis kelamin laki-laki/wanita, dengan kriteria usia mulai diatas 18 tahun sampai 40 tahun keatas yang dianggap cukup mengerti memberikan penilaian yang obyektif.

Menurut Sugiono (2008), sampel adalah bagian jumlah dan karakteristik yang dimiliki oleh populasi tersebut, pengambilan sampel dilakukan dengan pertimbangan faktor keterbatasan yang tidak memungkinkan seluruh populasi untuk diteliti. Adapun penelitian menggunakan rumus Slovin karena dalam penarikan sampel, jumlahnya harus representative agar hasil penelitian dapat digeneralisasikan dan perhitungannya pun tidak memerlukan tabel jumlah sampel, namun dapat dilakukan dengan rumus dan perhitungan sederhana. Rumus Slovin untuk menentukan sampel adalah :

$$
\mathrm{n}=\frac{N}{1+\mathrm{N}(\mathrm{e})^{2}}
$$

Keterangan :

$\mathrm{n}=$ Ukuran sampel

$\mathrm{N}=$ Ukuran Populasi

$\mathrm{E}=$ Persentase kelonggaran ketelitian kesalahan pengambilan sampel yang masih bisa ditolerir; $\mathrm{e}=0,1$

dalam rumus Slovin ada ketentuan sebagai berikut :

Nilai e $=0,1(10 \%)$ untuk populasi jumlah besar

Nilai e $=0,2(20 \%)$ untuk populasi jumlah kecil

Jumlah populasi dalam penelitian ini adalah sejumlah nasabah. Sehingga presentase kelonggaran yang digunakan adalah $10 \%$. Untuk mengetahui sampel penelitian, berikut perhitungannya :

$$
\mathrm{n}=\frac{250}{1+250(0,1)^{2}}=71,42
$$

jumlah sampel dibulatkan menjadi 72

Berdasarkan perhitungan diatas sampel yang menjadi responden dalam penelitian ini sebanyak 72 orang. Dalam penelitian ini menggunakan Non Probability, Non Probability adalah teknik pengambilan sampling dengan pengambilan sampel yang tidak memberi peluang atau kesempatan sama bagi setiap unsur atau anggota populasi untuk dipilih menjadi sampel (Umar, 2005). Variabel yang digunakan dalam penelitian ini terdiri dari 5 variabel yaitu :

Untuk variabel bebas atau independen $(\mathrm{X})$ adalah :

$\mathrm{X}_{1} \quad$ : Realibility (kehandalan)

$\mathrm{X}_{2} \quad$ :Responsiveness (daya tanggap)

$\mathrm{X}_{3} \quad$ : Asurance (jaminan)

$\mathrm{X}_{4} \quad$ : Emphaty (peduli)

$\mathrm{X}_{5} \quad$ : Tangible (bentuk fisik) 
Dan untuk variable terikat atau tidak bebas / dependen (Y) adalah :

Y : tingkat kepuasan nasabah di PT. Bank Mandiri (persero).Tbk cabang Gedangan Sidoarjo

Penelitian dirancang untuk mengetahui adanya analisa pelayanan service frontliner untuk meningkatkan kepuasaan nasabah di PT. Bank Mandiri (persero) Tbk cabang Gedangan Sidoarjo sehingga dapat memberikan pelayanan yang lebih baik, dapat meningkatkan jumlah nasabah. Alat uji yang digunakan adalah teknik analisis regresi linier berganda dengan software SPSS 18.0.

1. Uji Validitas

Uji validitas digunakan untuk menunjukkan ukuran yang benar - benar mengukur apa yang hendak diukur(Sunyoto, 2009:106). Uji validitas digunakan untuk mengukur sah atau valid tidaknya suatu kuesioner. Suatu kuesioner dikatakan valid jika pertanyaan pada kuesioner mampu untuk mengungkapkan sesuatu yang diukur oleh kuesioner tersebut. Jadi validitas ingin mengukur apakah pertanyaan dalam kuesioner yang sudah kita buat betul - betul dapat mengukur apa yang hendak kita ukur (Ghozali, 2002:49). Pengujian validitas dimaksudkan untuk mengetahui tingkat valid tidaknya instrumen kuisioner yang digunakan dalam pengumpulan data. Cara yang digunakan adalah dengan analisis item, dimana setiap nilai yang ada pada setiap butir pertanyaan dikorelasikan dengan nilai total seluruh butir pertanyaan untuk suatu variabel dengan menggunakan rumus kolerasi product momet (Sugiono, 2006). Apabila dilihat dari tingkat signifikan masing - masing item pernyataan memiliki nilai kurang dari $5 \%$, hal ini berarti item pernyataan tersebut tidak valid.

Dalam hal ini digunakan beberapa butir pertanyaan yang dapat secara tepat mengungkapkan variabel yang diukur tersebut. Untuk mengukur tingkat validitas dapat digunakan dengan cara mengkorelasikan antara skor butir pertanyaan dengan total skor kuesioner atau variabel. Hipotesis yang diajukan adalah :

Ho : Skor butir pertanyaan berkolerasi positif dengan total skor konstruk.

Ha : Skor butir pertanyaan tidak berkorelasi postif dengan total skor konstruk.

Uji validitas dilakukan dengan membandingkan nilai $r$ hitung dengan $r$ tabel untuk tingkat signifikansi 5 persen dari degree of freedom (af) $=n-2$, dalam hal ini $n$ adalah jumlah sampel. Jika $\mathrm{r}$ dihitung $>\mathrm{r}$ tabel maka pertanyaan atau indikator tersebut dinyatakan valid, demikian sebaliknya bila $r$ hitung $<\mathrm{r}$ tabel maka pertanyaan atau indikator tersebut dinyatakan tidak valid (Ghozali, 2005).

\section{Uji Reabilitas}

Uji reabilitas merupakan alat untuk mengukur suatu kuesioner yang merupakan indikator dari variabel atau konstruk. Suatu kuesioner dikatakan reliable atau handal jika jawaban seseorang terhadap pertanyaan adalah konsisten atau stabil dari waktu ke waktu (Ghozali, 2005). Pengukuran reabilitas dilakukan dengan cara one shot atau pengukuran sekali saja dengan alat bantu SPSS uji statistik Cronbach Alpha (a). Suatu 
konstruk atau variabel dikatakan reliable jika memberikan nilai Cronbach Alpha > 0.60 (Nunnally dalam Ghozali, 2005).

\section{METODE ANALISIS}

1. Analisis Regresi Berganda

Analis regresi berganda adalah persamaan regresi yang menggambarkan dan menjelaskan pengaruh lebih dari satu variabel bebas terhadap variabel terikat, dimana hubungan keduanya dapat digambarkan sebagai suatu garis lurus (Puspowarsito, 2008:49-50). Analisis regresi berganda digunakan untuk mengetahui pengaruh variabel bebas (realibity, responsiveness, assurance, emphaty, tangible ) terhadap varaibel terikat (.....) dengan formulasi sebagai berikut :

$$
Y=a+b_{1} X_{1}+b_{2} X_{2}+b_{3} X_{3}+b_{4} X_{4}+b_{5} X_{5}+e
$$

Dimana :

$\mathrm{Y}=$ Variabel terikat (tingkat kepuasan nasabah di PT. Bank Mandiri (persero)Tbk cabang Gedangan Sidoarjo)

$\mathrm{X}_{1}=$ Variabel kehandalan (realibility)

$\mathrm{X}_{2}=$ Variabel daya tanggap (responsiveness)

$\mathrm{X}_{3}=$ Variabel jaminan (assurance)

$\mathrm{X}_{4}=$ Variabel peduli (emphaty)

$\mathrm{X}_{5}=$ Variabel bentuk fisik (tangible)

$\mathrm{a}=$ Bilangan konstanta

$b_{1}, b_{2}, b_{n}=$ Koefisien regresi

$\mathrm{e}=$ Faktor pengganggu

\section{Analisis Koefisien Determinasi $\left(\mathrm{r}^{2}\right)$}

Koefisien determinasi adalah salah satu nilai statistik yang dapat digunakan untuk mengetahui apakah ada hubungan pengaruh antara dua variabel. Nilai koefisien determinasi menunjukkan presentase variasi nilai variabel dependen yang dapat dijelaskan oleh persamaan regresi yang dihasilkan. Besarnya presentase pengaruh semua variabel independent terhadap nilai variabel dependen dapat diketahui dari besarnya koefisien deteminasi $\left(\mathrm{r}^{2}\right)$ persamaan regresi. Besarnya koefisien determinasi adalah 0 sampai dengan semakin mendekati 0 besarnya koefisien determinasi $\left(r^{2}\right)$ suatu persamaan regresi, semakin kecil pula pengaruh semua variabel independent terhadap nilai variabel dependent. Sebaliknya, semakin mendekati 1 besarnya koefisien determinasi $\left(\mathrm{r}^{2}\right)$ suatu persamaan regresi, semakin besar pula pengaruh semua variabel independent terhadap variabel dependent. 


\section{HASIL DAN PEMBAHASAN}

Untuk menguji hipotesis penelitian pengaruh secara simultan variabel bebas terhadap variabel terikat digunakan uji F. Hasil uji F sesuai dengan perhitungan SPSS dapat dilihat pada tabel 1 .

Tabel 1.

Hasil Perhitungan Uji F

\begin{tabular}{|ll|c|c|c|c|c|}
\hline \multicolumn{1}{|c|}{ Model } & Sum of Squares & df & Mean Square & F & Sig. \\
\hline 1 & Regression & 2.224 & 5 & .445 & 22.286 & $.000^{\mathrm{a}}$ \\
& Residual & 1.317 & 66 & .020 & & \\
& Total & 3.541 & 71 & & & \\
\hline
\end{tabular}

Langkah - langkah pengujian :

$\mathrm{H}_{\mathrm{a}}=$ Terdapat pengaruh yang signifikan variabel reliability $\left(\mathrm{X}_{1}\right)$, responsiveness $\left(\mathrm{X}_{2}\right)$,

assurance $\left(\mathrm{X}_{3}\right)$, emphaty $\left(\mathrm{X}_{4}\right)$, dan tangible $\left(\mathrm{X}_{5}\right)$ terhadap kepuasan nasabah.

$\mathrm{H}_{0}=$ Tidak terdapat pengaruh signifikan variabel reliability $\left(\mathrm{X}_{1}\right)$, responsiveness

$\left(\mathrm{X}_{2}\right)$,assurance $\left(\mathrm{X}_{3}\right)$, emphaty $\left(\mathrm{X}_{4}\right)$, dan tangible $\left(\mathrm{X}_{5}\right)$ terhadap kepuasan nasabah.

Dari hasil analisis regresi linier berganda diperoleh $\mathrm{F}_{\text {hitung }}$ sebesar $22.285>$ dari $\mathrm{F}$ Tabel sebesar 2.346 atau dengan nilai signifikansi sebesar 0.000 dimana nilai signifikansi tersebut lebih kecil dari taraf signifikansi $=0,05$, maka dapat disimpulkan $\mathrm{H}_{\mathrm{o}}$ ditolak dan $\mathrm{H}_{\mathrm{a}}$ diterima, hal ini berarti reliability $\left(\mathrm{X}_{1}\right)$, responsiveness $\left(\mathrm{X}_{2}\right)$, assurance $\left(\mathrm{X}_{3}\right)$, emphaty $\left(\mathrm{X}_{4}\right)$, dan tangible $\left(\mathrm{X}_{5}\right)$ secara bersama-sama mempunyai pengaruh yang signifikan terhadap kepuasan nasabah $(\mathrm{Y})$. Cara mencari df di $\mathrm{F}_{\text {tabel }}$ adalah dengan rumus $\mathrm{df}=\mathrm{n}-\mathrm{k}-1$.

Untuk menguji pengaruh variabel bebas secara sendiri / parsial terhadap variabel terikat digunakan Uji t. Hasil Uji t sesuai dengan perhitungan SPSS dapat dilihat pada tabel 2

Tabel 2.

Hasil Perhitungan Uji t

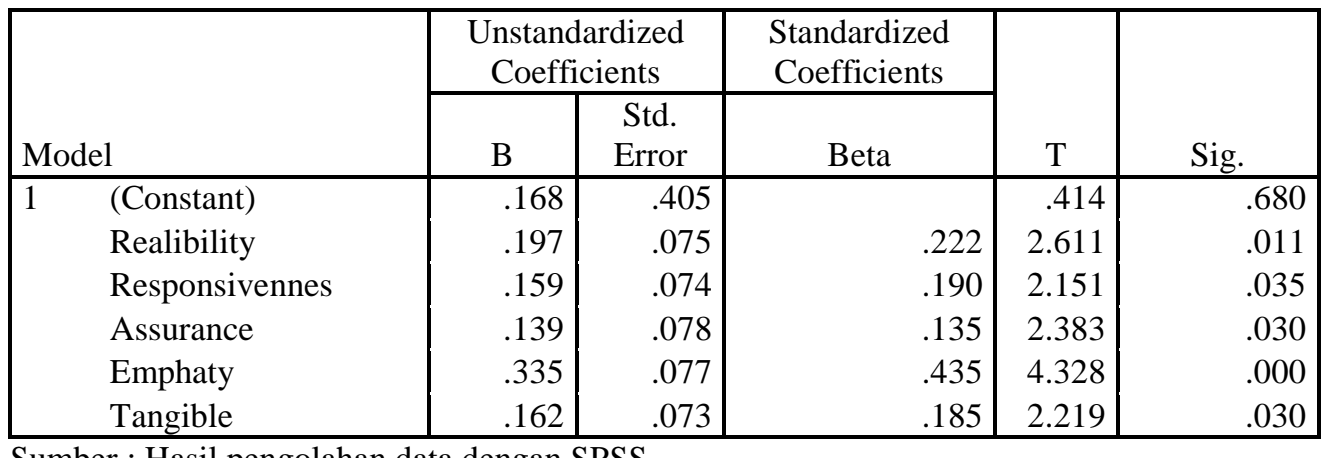

Sumber : Hasil pengolahan data dengan SPSS

Langkah-langkah pengujian :

1. Uji parsial antara variabel komitmen organisasi internal $\left(\mathrm{X}_{1}\right)$ terhadap kepuasan kerja (Y)

1. $\mathrm{H}_{0}: \mathrm{b}_{1}=0$ 
Artinya variabel komitmen organisasi internal $\left(\mathrm{X}_{1}\right)$ tidak mempunyai pengaruh yang signifikan terhadap variabel kepuasan kerja (Y).

2. $\mathrm{H}_{1}: \mathrm{b}_{1} \neq 0$

Artinya variabel komitmen organisasi internal $\left(\mathrm{X}_{1}\right)$ mempunyai pengaruh yang signifikan terhadap variabel kepuasan kerja (Y).

3. Membandingkan tingkat probabilitas signifikan (P Value) dengan $\alpha(0,05)$.

Apabila Probabilitas signifikan ( $\mathrm{P}$ Value $)<0,05, \mathrm{H}_{0}$ ditolak

Apabila Probabilitas signifikan (P Value $) \geq 0,05, \mathrm{H}_{0}$ diterima

Pada tabel 1 diatas dapat dilihat maka dapat disimpulkan bahwa variabel :

1. $\mathrm{H}_{\mathrm{a}}=$ Terdapat pengaruh yang signifikan Variabel reliability $\left(\mathrm{X}_{1}\right)$, responsiveness $\left(\mathrm{X}_{2}\right)$, assurance $\left(\mathrm{X}_{3}\right)$, emphaty $\left(\mathrm{X}_{4}\right)$, dan tangible $\left(\mathrm{X}_{5}\right)$ terhadap kepuasan nasabah.

2. $\mathrm{H}_{\mathrm{o}}=$ Tidak terdapat pengaruh signifikan Variabel reliability $\left(\mathrm{X}_{1}\right)$, responsiveness $\left(\mathrm{X}_{2}\right)$, assurance $\left(\mathrm{X}_{3}\right)$, emphaty $\left(\mathrm{X}_{4}\right)$, dan tangible $\left(\mathrm{X}_{5}\right)$ terhadap kepuasan nasabah.

Pada tabel 2 diatas dapat dilihat bahwa dalam uji $\mathrm{F}$ diperoleh $\mathrm{F}_{\text {hitung }}$ sebesar $22.285>$ dari F Tabel sebesar 2.346 atau dengan nilai signifikansi sebesar 0.000 dimana nilai signifikansi tersebut lebih kecil dari taraf signifikansi=0,05. maka dapat disimpulkan $\mathrm{H}_{\mathrm{o}}$ ditolak dan $\mathrm{H}_{\mathrm{a}}$ diterima, hal ini berarti reliability $\left(\mathrm{X}_{1}\right)$, responsiveness $\left(\mathrm{X}_{2}\right)$, assurance $\left(\mathrm{X}_{3}\right)$, emphaty $\left(\mathrm{X}_{4}\right)$, dan tangible $\left(\mathrm{X}_{5}\right)$ secara bersama-sama mempunyai pengaruh yang signifikan terhadap kepuasan nasabah (Y). Untuk menguji pengaruh variabel bebas secara dominan terhadap variabel terikat dengan perhitungan SPSS dapat dilihat pada tabel berikut ini :

Tabel 3.

Hasil Uji regresi

\begin{tabular}{|c|c|c|c|c|c|c|c|c|c|c|c|}
\hline & \multirow[b]{2}{*}{ Model } & \multicolumn{2}{|c|}{$\begin{array}{l}\text { Unstandardized } \\
\text { Coefficients }\end{array}$} & \multirow{2}{*}{$\begin{array}{c}\begin{array}{c}\text { Standardized } \\
\text { Coefficients }\end{array} \\
\text { Beta }\end{array}$} & \multirow[b]{2}{*}{$\mathrm{T}$} & \multirow[b]{2}{*}{ Sig. } & \multicolumn{3}{|c|}{ Correlations } & \multicolumn{2}{|c|}{ Collinearity Statistics } \\
\hline & & $\mathrm{B}$ & Std. Error & & & & Zero-order & Partial & Part & Tolerance & VIF \\
\hline \multirow[t]{6}{*}{1} & (Constant) & .168 & .405 & & .414 & .680 & & & & & \\
\hline & Realibility & .197 & .075 & .222 & 2.611 & .011 & .497 & .306 & .196 & .782 & 1.279 \\
\hline & $\begin{array}{l}\text { Responsive } \\
\text { nnes }\end{array}$ & .159 & .074 & .190 & 2.151 & .035 & .522 & .256 & .161 & .720 & 1.389 \\
\hline & Assurance & .139 & .078 & .135 & 1.783 & .039 & .189 & .214 & .134 & .982 & 1.018 \\
\hline & Emphaty & .335 & .077 & .435 & 4.328 & .000 & .718 & .470 & .325 & .557 & 1.795 \\
\hline & Tangible & .162 & .073 & .185 & 2.219 & .030 & .436 & .263 & .167 & .814 & 1.229 \\
\hline
\end{tabular}

Sumber : Hasil pengolahan data dengan SPSS

Dari persamaan tersebut diatas dapat dijelaskan sebagai berikut :

1. Konstanta $\left(\beta_{0}\right)$ sebesar 0,168 menunjukkan pengaruh reliability $\left(\mathrm{X}_{1}\right)$, responsivenees $\left(\mathrm{X}_{2}\right)$, assurance $\left(\mathrm{X}_{3}\right)$, emphaty $\left(\mathrm{X}_{4}\right)$, dan tangible $\left(\mathrm{X}_{5}\right)$ terhadap kepuasan nasabah (Y), artinya apabila variabel bebas tersebut sama dengan 0 (konstan), maka di prediksikan kepuasan nasabah akan naik sebesar 0,168

2. Koefisien regresi untuk reliability $\left(\mathrm{X}_{1}\right)$ sebesar 0,197 . Berarti jika reliability $\left(\mathrm{X}_{1}\right)$ naik sebesar satu satuan, maka kepuasan nasabah (Y) akan mengalami kenaikan sebesar 0,197dengan anggapan variabel bebas lainnya konstan atau nol. 
3. Koefisien untuk responsiveness $\left(\mathrm{X}_{2}\right)$ sebesar 0,159. Berarti jika responsiveness $\left(\mathrm{X}_{2}\right)$ naik sebesar satu satuan, maka kepuasan nasabah (Y) akan mengalami kenaikan sebesar 0,159. Dengan anggapan variabel bebas lainnya konstan atau nol.

4. Koefisien regresi untuk assurance $\left(\mathrm{X}_{3}\right)$ sebesar 0,139 . Berarti jika assurance $\left(\mathrm{X}_{3}\right)$ naik sebesar satu satuan, maka kepuasan nasabah $(\mathrm{Y})$ akan mengalami kenaikan sebesar 0,139. Dengan anggapan variabel bebas lainnya konstan atau nol.

5. Koefisien regresi untuk emphaty $\left(\mathrm{X}_{4}\right)$ sebesar 0,335. Berarti jika emphaty $\left(\mathrm{X}_{4}\right)$ naik sebesar satu satuan, maka kepuasan nasabah (Y) akan mengalami kenaikan sebesar 0,335 . Dengan anggapan variabel bebas lainnya konstan atau nol.

6. Koefisien regresi untuk tangible $\left(\mathrm{X}_{5}\right)$ sebesar 0,162 . Berarti jika tangible $\left(\mathrm{X}_{4}\right)$ naik sebesar satu satuan, maka kepuasan nasabah $(\mathrm{Y})$ akan mengalami kenaikan sebesar 0,162 . Dengan anggapan variabel bebas lainnya konstan atau nol.

Berdasarkan hasil print out atau output SPSS 17.0 for windows pada lampiran serta berdasarkan pada hipotesis yang telah ditetapkan menunjukkan bahwa :

1. Dari hasil analisis regresi linier berganda dalam uji $\mathrm{F}$ diperoleh $\mathrm{F}_{\text {hitung }}$ sebesar 22.285> dari F Tabel sebesar 2.346 atau dengan nilai signifikansi sebesar 0.000 dimana nilai signifikansi tersebut lebih kecil dari taraf signifikansi $=0,05$. maka dapat disimpulkan $\mathrm{H}_{\mathrm{o}}$ ditolak dan $\mathrm{H}_{\mathrm{a}}$ diterima, hal ini berarti reliability $\left(\mathrm{X}_{1}\right)$, responsiveness $\left(\mathrm{X}_{2}\right)$, assurance $\left(\mathrm{X}_{3}\right)$, emphaty $\left(\mathrm{X}_{4}\right)$, dan tangible $\left(\mathrm{X}_{5}\right)$ secara bersama - sama mempunyai pengaruh yang signifikan terhadap kepuasan nasabah $(\mathrm{Y})$.

2. Dan dari uji $\mathrm{t}$ diperoleh $\mathrm{t}_{\text {hitung }}$ untuk masing - masing variabel yaitu variabel realibility sebesar 2.611; variabel responsiveness sebesar 2.155; variabel assurance sebesar 2.383; variable emphaty sebesar 4.328; variabel tangible sebesar 2.219. yang nilainya lebih besar dari $\mathrm{t}_{\text {tabel }}$ yaitu sebesar 1.997 yang berarti menyatakan bahwa variabel stress reliability $\left(\mathrm{X}_{1}\right)$, responsiveness $\left(\mathrm{X}_{2}\right)$, assurance $\left(\mathrm{X}_{3}\right)$, emphaty $\left(\mathrm{X}_{4}\right)$, dan tangible $\left(\mathrm{X}_{5}\right)$, secara sendiri - sendiri (parsial) mempunyai pengaruh terhadap variabel kepuasan nasabah.

\section{KESIMPULAN}

Dari hasil penelitian dan pembahasan yang digunakan sesuai dengan tujuan dan hipotesis yang dikemukakan dengan alisis regresi linier berganda, maka dapat ditarik kesimpulan adalah dari hasil analisis regresi linier berganda dalam uji $\mathrm{F}$ diperoleh $\mathrm{F}_{\text {hitung }}$ sebesar 22.285> dari F Tabel sebesar 2.346 atau dengan nilai signifikansi sebesar 0.000 dimana nilai signifikansi tersebut lebih kecil dari taraf signifikansi $=0,05$. maka dapat disimpulkan $\mathrm{H}_{\mathrm{o}}$ ditolak dan $\mathrm{H}_{\mathrm{a}}$ diterima, hal ini berarti reliability $\left(\mathrm{X}_{1}\right)$, responsiveness $\left(\mathrm{X}_{2}\right)$, assurance $\left(\mathrm{X}_{3}\right)$, emphaty $\left(\mathrm{X}_{4}\right)$, dan tangible $\left(\mathrm{X}_{5}\right)$ secara bersama-sama mempunyai pengaruh yang signifikan terhadap kepuasan nasabah $(\mathrm{Y})$.

Dan dari uji t untuk mengetahui pengaruh parsial diperoleh realibility sebesar 2.611; variabel responsiveness sebesar 2.155; variabel assurance sebesar 2.383; 
variabel emphaty sebesar 4.328; variabel tangible sebesar 2.219. yang nilainya lebih besar dari $t_{\text {tabel }}$ yaitu sebesar 1.997 yang berarti menyatakan bahwa variabel reliability $\left(\mathrm{X}_{1}\right)$, responsiveness $\left(\mathrm{X}_{2}\right)$, assurance $\left(\mathrm{X}_{3}\right)$, emphaty $\left(\mathrm{X}_{4}\right)$, dan tangible $\left(\mathrm{X}_{5}\right)$, secara sendiri-sendiri (parsial) mempunyai pengaruh terhadap variabel kepuasan nasabah.

\section{DAFTAR PUSTAKA}

Amir, Taufik. 2005. Dinamika pemasaran. Jakarta : PT. Raja Grafindo Persada

Gerald Zaltaman. 2005. Perilaku Konsumen. Jakarta : Bina Ilmu

Husein, Umar. 2006. Riset Pemasaran dan Perilaku Konsumen. Jakarta : Gramedia Pustaka Utama

Kotler, Philip.2007. Prinsip-prinsip Pemasaran. Jakarta : Prenhallindo : jilid 2

Nitisemito, Alex S. 2006. Manajemen Personalia. Jakarta : Graha Indonesia

Parasuraman. 2012. Layanan Kualitas Jasa. Ghalia Indonesia.

Sugiyono. 2011. Metode Penelitian Kuantitatif, Kualitatif dan $R \&$ D. Bandung : CV. AFBETA

Sutopo dan Suryanto, Adi. 2006. Pelayanan Prima. Jakarta: Lembaga Administrasi Negara Republik Indonesia.

Sunarwan, U. 2003. Perilaku Konsumen Teoridan dan Penerapannya Dalam Pemasaran. Jakarta : Ghalia Indonesia

Tjiptono, Fandy.2006. Pemasaran Jasa. Yogyakarta : Andi offset

Tjiptono, Fandy dan chandra.2007.Service Quality \&Statistik Faction. Edisi Yogyakarta.

Tjiptono, Fandy. 2010. Prinsip-Prinsip Total Quality Service. Cetakan Kedua, Yogyakarta.

Umar, husein.2006. Riset Pemasaran dan Perilaku Konsumen. Andy Offset, Yogyakarta

Umar. 2006. Metode Riset Bisnis. Jakarta : PT. Gramedia Pustaka Utama

Vincent Gaspersz. 2005.Total Quality Management. Jakarta : Gramedia Pustaka Utama www. mampu.gov.my. (diakses 20 januari 2015)

www.unila.ac.id/fisip-admneg/mambo. 2007(diakses 10 februari 2015)

Winardi, 2006, Azas-Azas Marketing, Penerbit PT. Mandar Maju 